\title{
Comparative Relaxant Effects of Ataciguat and Zaprinast on Sheep Sphincter of Oddi
}

\author{
Erol Çakmak ${ }^{1}$, Özlem Yönem ${ }^{1}$, Bülent Saraç², Mesut Parlak ${ }^{3}$ Cumali Çelik ${ }^{4}$, Hilmi Ataseven ${ }^{5}$ İhsan Bağcivan² \\ ${ }^{1}$ Department of Gastroenterology, Cumhuriyet University School of Medicine, Sivas, Turkey \\ ${ }^{2}$ Department of Pharmacology, Cumhuriyet University School of Medicine, Sivas, Turkey \\ ${ }^{3}$ Department of Pharmacology, Sivas Numune Hospital, Sivas, Turkey \\ ${ }^{4}$ Department of Internal Medicine, Sivas Numune Hospital, Sivas, Turkey \\ ${ }^{5}$ Department of Gastroenterology, Sivas Numune Hospital, Sivas, Turkey
}

Background: Relaxing the sphincter of Oddi (SO) is an important process during endoscopic retrograde cholangiopancreatography (ERCP) procedures. This issue suggests that the easier the sphincterotomy and cannulation, the more post-ERCP complications decrease.

Aims: To compare the relaxant effects of ataciguat (a novel soluble guanylyl cyclase activator) and zaprinast (an inhibitor of phosphodiesterase 5) on sheep SO in vitro, thus testing whether they can be used during ERCP.

Study Design: Animal experimentation.

Methods: Sheep SO rings were placed in tissue baths and their isometric tension to ataciguat and zaprinast were tested. We also tested their isometric tension against ataciguat in the presence of $1 \mathrm{H}-(1,2,4)$ oxadiazole $(4,3-\mathrm{a})$ quinoxalin- 1-one (ODQ) which is a soluble guanylyl cyclase inhibitor. Results: Ataciguat and zaprinast both triggered concentration addicted relaxation on sheep SO rings $(p=0.0018$, $p=0.0025$ respectively) but the relaxation of the ataciguat was significantly greater than that of zaprinast at all concentrations $(p=0.0024)$. It was observed that decreased relaxation responses were initiated by ataciguat in the presence of ODQ ( $\mathrm{p}=0.0012)$.

Conclusion: Ataciguat and zaprinast both have relaxing effects on sphincter of Oddi, although that of zaprinast is lower. We believe that ataciguat and zaprinast can be used in ERCP procedures in order to relax the sphincter of Oddi and thus can be used locally in order to decrease complications. Keywords: Ataciguat, Oddi's sphincter, zaprinast
The sphincter of Oddi (SO) has the ability to settle the drainage of bile into the duodenum, facilitates the filling of the gallbladder and stops reflux of the duodenal ingredients back into the common bile duct and pancreatic duct $(1,2)$. $\mathrm{SO}$ is a complex structure formed by smooth muscle fibers and a neural network and its motility and function are mediated through hormonal and neural pathways (2). Nitric oxide (NO) has been shown to induce neurogenic relaxation in SO as a response to myenteric nerve stimulation in clinical and experimental studies $(3,4)$. Disorders of the NO/cyclic guanosine monophosphate (NO/cGMP) pathway cause an inability to relax the sphincter and decrease the motility of the gastrointestinal system (5). Agents that act on the NO/cGMP pathway induce smooth muscle relaxation and reduce the contraction of sphincter smooth muscles (6).
Ataciguat, which is an aminobenzoic acid derivative and a new soluble guanylyl cyclase activator, activates guanylyl cyclase (GC) and induces the transformation of guanosine triphosphate (GTP) to cGMP and the activation of protein kinase (7). Activated protein kinase reduces the ionized calcium concentration and sensitivity in the smooth muscle cells, causing relaxation in smooth muscles $(8,9)$. There are many studies in the literature which state that soluble guanylyl cyclase activators cause relaxation in all smooth muscles as well as SO and gastrointestinal smooth muscles $(7,8)$.

Zaprinast, a phosphodiesterase 5 (PDE-5) inhibitor like the clinical drug sildenafil, is a precursor to the chemically-related cGMP-dependent $(9,10)$. Zaprinast increases intracellular cGMP levels by inhibiting PDEs that reduce smooth muscle relaxation in many tissues, especially in the gastrointestinal

This study was presented as an oral presentation at the $30^{\text {th }}$ Turkish Gastroenterology Week, 11-15 September 2013, Antalya, Turkey.

Address for Correspondence: Dr. Erol Çakmak, Department of Gastroenterology, Cumhuriyet University School of Medicine, Sivas, Turkey

Phone: +905052309495_e-mail:drecakmak@hotmail.com

Received: 8 October $2015 \quad$ Accepted: 18 March $2016 \quad$ DOI: 10.5152/balkanmedj.2016.15400

Available at www.balkanmedicaljournal.org

Cite this article as:

Çakmak E, Yönem Ö, Saraç B, Parlak M, Çelik C, Ataseven H, et al. Comparative relaxant effects of ataciguat and zaprinast on sheep sphincter of Oddi. Balkan Med

J 2016;33:453-7 
system $(11,12)$. Phosphodiesterase type 5 (PDE-5) has been defined in the esophageal sphincter, internal anal sphincter and pyloric sphincter in experimental studies $(13,14)$. The sGC/cGMP signaling pathway plays a significant role in the gastrointestinal system $(7,8)$.

Endoscopic retrograde cholangiopancreatography (ERCP) is an invasive procedure that is used for the diagnosis and treatment indifferent biliary and pancreatic canal pathologies (15). However, ERCP may lead to a number of serious complications including pancreatitis, hemorrhage, and perforation (15). Easy cannulation plays a critical role in both preventing these complications and shortening the duration of the procedure. Using pharmacological agents for relaxation of the SO can provide easier cannulation and therefore, a safer and shorter ERCP procedure $(15,16)$.

There is insufficient evidence in the literature that compares the relaxant effect of ataciguat and zaprinast on isolated sheep $\mathrm{SO}$ rings. We aimed to examine the direct effects of ataciguat and zaprinast via the sGC/cGMP signal transduction system of sheep SO in this study in order to find new candidate agents for the ERCP procedure.

\section{MATERIALS AND METHODS}

\section{Design of the study}

Ten male adult Anatolian Akkaraman sheep weighing from 38 to $45 \mathrm{~kg}$ were used in the present study. The study was approved by the local ethical committee of Cumhuriyet University School of Medicine. The sheep were sacrificed by cervical cuts in the slaughterhouse. Their abdomens were opened with a midline incision and SO was quickly removed and taken to the laboratory in previously aerated $\left(95 \% \mathrm{O}_{2}\right.$ and $\left.5 \% \mathrm{CO}_{2}\right)$ Krebs' bicarbonate solution that consisted of $120 \mathrm{mmol} / \mathrm{L}$ $\mathrm{NaCl}, 4.6 \mathrm{mmol} / \mathrm{L} \mathrm{KCl}, 2.5 \mathrm{mmol} / \mathrm{L} \mathrm{CaCl}, 1.2 \mathrm{mmol} / \mathrm{L}$ $\mathrm{MgCl}_{2}, 22 \mathrm{mmol} / \mathrm{L} \mathrm{NaHCO}_{3}, 11.5 \mathrm{mmol} / \mathrm{L} \mathrm{NaH}_{2} \mathrm{PO}_{4}$ and 11.5 $\mathrm{mmol} /$ glucose. SO muscle rings were placed into in a $10 \mathrm{~mL}$ tissue bath that contained pre-aerated Krebs' bicarbonate solution at $37^{\circ} \mathrm{C}$. The upper end of a $1.5 \mathrm{~g}$ SO ring was tied to an isometric transducer (Grass FT 03; MA, USA). In order to get a stable baseline measurement, SO muscle rings were sluiced every $15 \mathrm{~min}$ and left to establish equilibrium for about $60-90$ min. Before each drug application, we washed the tissue at least twice and eliminated the drug by soaking it in an organ bath for at least half an hour. Once the tissue was free of the drug, a new set of drugs was applied.

\section{Isometric measurements}

After reaching equilibrium, submaximal concentration of carbachol $\left(10^{-6} \mathrm{~mol} / \mathrm{L}\right)$ was applied in order to get contraction in SO tissues. This concentration of carbachol was decided in previous experiments (6). After completing contraction studies performed using carbachol, we measured the relaxation responses to ataciguat $\left(10^{-9}-10^{-4} \mathrm{~mol} / \mathrm{L}\right.$ ) (a new soluble guanylyl cyclase activator) and zaprinast $\left(10^{-9}-10^{-4} \mathrm{~mol} / \mathrm{L}\right)$ (a phosphodiesterase-5 inhibitor) in a cumulative manner. We also measured relaxation responses to ataciguat in the presence of $1 \mathrm{H}-(1,2,4)$ oxadiazole $(4,3-\mathrm{a})$ quinoxalin-1-one (ODQ) (an inhibitor of soluble guanylyl cyclase).

\section{Statistical analysis}

When alpha $(\alpha)$ levels are considered 0.05 , the beta $(\beta)$ level as 0.20 and $1-\beta$ level as $0.80,10$ sheep were recruited into each group. The analytical power of the test was found to be $\mathrm{p}=0.80310$.

Carbachol-induced contractions were considered as reference values. Relaxation responses were expressed as a percentage of the carbachol-induced contractions. The relaxation effects of cumulative concentrations of ataciguat and zaprinast on carbachol-induced contractions in the absence or presence of ODQ were measured. Values for $-\log 10 \mathrm{EC}_{50}\left(\mathrm{pD}_{2}\right)$ and mean maximal inhibition $\left(\mathrm{E}_{\max }\right)$ were compared. The concentration-response data found in each individual experiment were planned as the response/concentration against the response, producing a linear association in each experiment, as predicted from the Scatchard equation for drug-receptor interaction: Response/concentration $=-1 / \mathrm{EC}_{50} \mathrm{x}$ response + $\mathrm{E}_{\max } / \mathrm{EC}_{50}$.

After entering the data obtained from our study in the SPSS program (data 22.0), Oddi sphincter concentration-dependent relaxation levels, $\mathrm{E}_{\max }$ and $\mathrm{pD}_{2}$ values when parametric assumptions could not be performed (One sample KolmogrovSmirnov), the Friedman test and Bonferroni test were used for variations of groups among themselves. When groups were compared in terms of each single dose concentration, the Kruskal Wallis test was used. For all analyses, $p$ values $<0.05$ were accepted as significant. Statistical analyses were performed using Statistical Package for the Social Sciences software 22.0 (IBM SPSS Statistics; Armonk, NY, IL, USA).

\section{Drugs}

Drugs included carbachol, ODQ, ataciguat, and zaprinast. Drugs were supplied by Santa-Cruz (carbachol, ODQ, ataciguat and zaprinast; Santa-Cruz Biotechnology; Texas, USA). Other than ODQ, which was dissolved in dimethylsulfoxide and then diluted with distilled water, all of the drugs were dissolved only in distilled water in order to obtain the reduced concentrations of these drugs. Drug-containing solutions were prepared only at the time of the experiments. 


\section{RESULTS}

Ataciguat $\left(10^{-9}-10^{-4} \mathrm{~mol} / \mathrm{L}\right)$ induced concentration-dependent relaxations in SO rings pre-contracted by carbachol $(\mathrm{p}=0.0018)$. The relaxation responses induced by ataciguat were significantly decreased in the presence of ODQ $\left(10^{-5}\right.$ $\mathrm{mol} / \mathrm{L}$ ) beginning from the $10^{-8}-\mathrm{mol} / \mathrm{L}$ concentration $(\mathrm{p}=0.0012)$ (Figure 1). Zaprinast $\left(10^{-8}-10^{-4} \mathrm{~mol} / \mathrm{L}\right)$ induced concentration-dependent relaxation in SO rings was pre-contracted by carbachol as well $(\mathrm{p}=0.0025)$ (Figure 2$)$. The relaxation of the ataciguat was significantly greater than the relaxation of zaprinast at all concentrations in $\mathrm{SO}$ rings $(\mathrm{p}=0.0024)$ ( $\mathrm{E}_{\text {maks }}$ values $79.2 \pm 5.8$ for ataciguat, $52.0 \pm 6.0$ for zaprinast).

Table 1 presents the $\mathrm{pD}_{2}$ and $\mathrm{E}_{\max }$ values of ataciguat and zaprinast on SO rings previously contracted by carbachol. We could not find any significant difference between ataciguat and zaprinast in $\mathrm{pD}_{2}$ values $(\mathrm{p}=0.091)$.

\section{DISCUSSION}

In this study, we aimed to establish whether the new agents affecting the sGC/cGMP pathway can be promising for SO relaxation. For this purpose, we used ataciguat, a new guanylate cyclase activator, and zaprinast, a phosphodiesterase type 5 inhibitor. Ataciguat and zaprinast induced concentrationdependent relaxations in $\mathrm{SO}$ rings previously contracted by carbachol. The relaxation effect of ataciguat was significantly greater than that of zaprinast at all concentrations in SO rings.

Endoscopic retrograde cholangiopancreatography is a complex and risky procedure used for the diagnosis and treatment of hepatobiliary and pancreatic diseases $(15,16)$. It is an invasive procedure and short-term complications including hemorrhage, pancreatitis and perforation can occur $(17,18)$. By facilitating cannulation and sphincterotomy with the help of appropriate pharmacological agents, it is possible to lower ERCP related complications.

Nitric oxide has the capacity to regulate the muscle tone of the pancreatobiliary junction, sphincter of the lower esophagus and pylorus. It is synthesized by NO synthase (NOS) from the L-Arginine molecule. It then activates guanylate cyclase in the cytosol of smooth muscle cells, which transforms GTP to cGMP. The cGMP activates protein kinase $\mathrm{G}$ and ion channels. As a result of these alterations, intracellular calcium decreases in the smooth muscle cells and the sphincter relaxes. The physiological effect of cGMP is terminated by the enzyme phosphodiesterase $(1,2)$.

Guanylyl cyclase is an important part of the NO/cGMP pathway and its existence has been shown in many systems such as the cardiovascular, nervous, urogenital and gastroin-

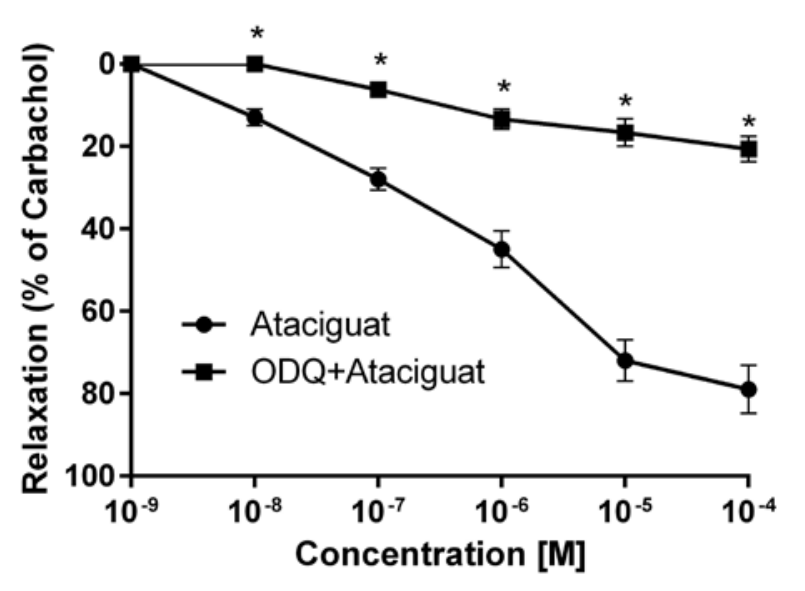

FIG. 1. Relaxation responses induced by ataciguat (10-9-10-4 mol/L) in the presence and absence of ODQ (10-5 mol/L) on isolated sheep SO rings. Relaxations are expressed as the percentage of carbachol $(10-6 \mathrm{~mol} / \mathrm{L})$-induced pre-contraction and are shown as mean $\pm S D$.

${ }^{*}$ Statistically different from agent only $(p=0.0012)$.

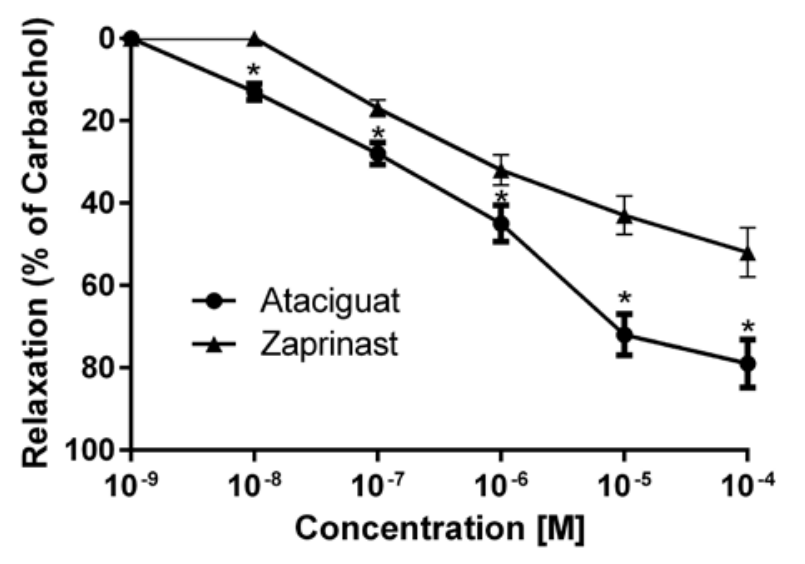

FIG. 2. Relaxation responses induced by ataciguat (10-9-10-4 mol/L) and zaprinast (10-9-10-4 mol/L) on isolated sheep SO rings. Relaxations are expressed as percentage of carbachol (10-6 mol/L)-induced precontraction and shown as mean $\pm S D$.

*Statistically different from zaprinast $(p=0.0024)$.

testinal systems. GC activation results in increasing cGMP levels in cells and finally causes relaxation in smooth muscle cells of the cardiovascular and gastrointestinal systems (18). Some guanylyl cyclase activators are used in clinical practice for pulmonary hypertension, congestive heart failure and erectile dysfunction because of their relaxation effect on smooth muscles (19). GC is found in several locations in the gastrointestinal tract and it is denser, especially in the lower esophageal sphincter tissue and SO $(20,21)$. It has been shown in nitric oxide-sensitive GC knockout mice that gastrointestinal 
TABLE 1. $\mathrm{E}_{\max }$ and $\mathrm{pD}_{2}$ values for the relaxant effects of ataciguat and zaprinast alone and the ODQ + Ataciguat $\left(10-^{5} \mathrm{~mol} / \mathrm{L}\right)$ on sheep SO rings pre-contracted by carbachol $\left(10-{ }^{6} \mathrm{~mol} / \mathrm{L}\right)$

ODQ + Ataciguat (10-5 $\left.{ }^{5} \mathrm{~mol} / \mathrm{L}\right)$ on Sheep SO Rings Pre-contracted by Carbachol $\left(10-^{6} \mathrm{~mol} / \mathrm{L}\right)$

\begin{tabular}{lcc} 
& $\begin{array}{c}\text { Emaks } \\
\text { (\% of Carbachol) }\end{array}$ & $\mathbf{p D}_{\mathbf{2}}$ \\
\hline Ataciguat & $79.2 \pm 5.8$ & $6.52 \pm 0.10$ \\
ODQ + Ataciguat & $20.6 \pm 3.0^{*}$ & $6.70 \pm 0.14$ \\
Zaprinast & $52.0 \pm 6.0^{* *}$ & $5.92 \pm 0.09$ \\
\hline
\end{tabular}

Data were presented as mean $\pm \mathrm{SD}$ (standard deviation).

*Statistically different from only ataciguat $(\mathrm{p}=0.0012)$.

**Statistically different from zaprinast when compared with ataciguat $(\mathrm{p}=0.0024)$.

$\mathrm{E}_{\max }$ : maximum relaxant effect; $\mathrm{pD}_{2}$ : negative logarithm to base 10 of the EC50; ODQ: $1 \mathrm{H}-(1,2,4)$ oxadiazole $(4,3-\mathrm{a})$ quinoxalin-1-one

motility is reduced, which results in gastroparesis and pyloric stenosis (22). Several previous studies have shown that some sGC activators and some drugs that affect $\mathrm{NO} / \mathrm{sGC} / \mathrm{cGMP}$ cause relaxation of sheep SO $(6,22)$. Ataciguat is a new sGC activator. The vasodilator effect of ataciguat has been determined previously but no study regarding the effect of this drug on gastrointestinal system and sphincter of Oddi has been presented (23). In our study, a new sGC activator ataciguat induced significant and concentration-dependent relaxations in $\mathrm{SO}$ rings. Ataciguat-induced relaxations are significantly decreased in the presence of the GC inhibitor ODQ.

PDE-5 inhibitors prevent hydrolysis of cGMP leading to an increase in cGMP concentrations. Then, cGMP activates protein kinase and smooth muscle relaxation occurs (24). Several studies have shown that the inhibition of PDE-5 may be helpful in the cure of chronic anal fissure, erectile dysfunction, pulmonary hypertension and various vascular diseases (25-27). Experimental animal studies have shown that in the lower esophageal sphincter, internal anal sphincter and pyloric sphincter, zaprinast may increase cGMP levels, activate protein kinase and cause smooth muscle relaxation. For these reasons, since PDE-5 inhibitors can decrease motility and reduce basal sphincter pressure, these drugs have been found to be useful in medical therapy of dysfunction of SO and hypercontractile esophageal motility disorders $(28,29)$. Sildenafil, a PDE-5 inhibitor, creates concentration-dependent relaxation in the gallbladder. Cheon et al. (29) found that the PDE-5 inhibitor vardenafil also inhibited SO motility and reduced the basal SO pressure. They have also shown that the administration of local vardenafil before the ERCP procedure may reduce the tone of SO and allow the doctor to perform easy cannulation. Easy cannulation would help to decrease the incidence of post-ERCP pancreatitis. Zaprinast is a PDE-5 inhibitor that has been recognized for many years. The relaxing effect of zaprinast on the esophageal lower sphincter has been determined by Barnette et al. (30), but its effect on the sphinc- ter of Oddi has not been investigated until today. In our study, similarly, the PDE-5 inhibitor zaprinast induced significant concentration-dependent relaxations in SO rings.

In this study, when comparing the effects of ataciguat and zaprinast, the relaxant effect of ataciguat was more potent than zaprinast in sheep SO. The GC inhibitor ODQ significantly reduced the relaxation of ataciguat in $\mathrm{SO}$ rings. This confirms that relaxation caused by ataciguat may occur via the activation of sGC. Relaxations on the sphincter of Oddi induced by ataciguat and zaprinast in this study show parallel results with other studies regarding other sGC activators and PDE-5 inhibitors.

The strong and weak aspects of this study are as follows: the study needing to be in vitro is one of the weak aspects. Adjusting the study performed to in vivo may not always be possible. However, because the target drugs investigated in this study are used locally during ERCP, adjusting data obtained from this study to in vivo studies may be possible. Additionally, because the variables can be controlled by the investigator in an in vitro setting, much clearer comments concerning the mechanism of action of these drugs can be made, which is a strong aspect of the study.

In conclusion, our study results suggest that ataciguat, a new guanylate cyclase activator and to a lesser extent zaprinast, a phosphodiesterase-5 inhibitor, are preferable agents for the relaxation of SO. However, our results should be confirmed by further in vivo and clinical studies. Relaxed $\mathrm{SO}$ is one of the most important aspects in performing a successful ERCP procedure. We believe that this study will pave the way for the local use of these molecules providing faster ERCP procedures with fewer complications.

Ethics Committee Approval: Ethics committee approval was received for this study from the ethics committee of Cumhuriyet University School of Medicine (Date: 02.11.2011, Number: 2011-283).

\section{Informed Consent: N/A.}

Peer-review: Externally peer-reviewed.

Author contributions: Concept - E.C., O.Y., I.B.; Design - E.C.; Supervision - O.Y.; Resource - E.C.; Materials - B.S., M.P.; Data Collection and/or Processing - E.C., C.C.; Analysis and/or Interpretation - I.B., M.P.; Literature Search - E.C.; Writing - E.C., O.Y.; Critical Reviews - E.C., O.Y., H.A.

Conflict of Interest: No conflict of interest was declared by the authors.

Financial Disclosure: The authors declared that this study has received no financial support. 


\section{REFERENCES}

1. Bosch A, Peña LR. The sphincter of oddi. Dig Dis Sci 2007;52:1211-8. [Crossref]

2. Woods CM, Mawe GM, Toouli J, Saccone GT. The sphincter of Oddi: understanding its control and function. Neurogastroenterol Motil 2005;1:31-40. [Crossref]

3. Wells DG, Talmage EK, Mawe GM. Immunohistochemical identification of neurons in ganglia of the guinea pig sphincter of Oddi. J Comp Neurol 1995;352:106-16. [Crossref]

4. Mourelle M, Guarner F, Moncada S, Malagelada JR. The arginine/nitric oxide pathway modulates sphincter of Oddi motor activity in guinea pigs and rabbits. Gastroenterology 1993;105:1299-305. [Crossref]

5. Moncada S, Palmer RM, Higgs EA. Nitric oxide: Physiology, pathophysiology, and pharmacology. Pharmacol Rev 1991;43:109-42.

6. Sarac B, Durmus N, Bagcivan I, Altun A, Turan M, Sencan M. Investigation of relaxant effects of new agents affecting nitric oxide/cyclic guanosine monophosphate pathway on sheep oddi sphincter. Pancreas 2010;39:875-8. [Crossref]

7. Denninger JW, Marletta MA. Guanylate cyclase and the NO/ cGMP signaling pathway. Biochim Biophys Acta 1999;1411:33450. [Crossref]

8. Cosyns SM, Huyghe L, Thoonen R, Stasch JP, Brouckaert P, Lefebvre RA. Influence of cinaciguat on gastrointestinal motility in apo-sGC mice. Neurogastroenterol Motil 2014;26:157385. [Crossref]

9. Choi SH, Choi DH, Song KS, Shin KH, Chun BG. Zaprinast, an inhibitor of cGMP-selective phosphodiesterases, enhances the secretion of TNF-alpha and IL-1beta and the expression of iNOS and MHC class II molecules in rat microglial cells. $J \mathrm{Neu}$ rosci Res 2002;67:411-21. [Crossref]

10. Taniguchi Y, Tonai-Kachi H, Shinjo K. Zaprinast, a well-known cyclic guanosine monophosphate-specific phosphodiesterase inhibitor, is an agonist for GPR35. FEBS Lett 2006;580:5003-8. [Crossref]

11. Ballester C, Sarriá B, García-Granero E, Morcillo EJ, Lledó S, Cortijo J. Relaxation of the isolated human internal anal sphincter by sildenafil. Br J Surg 2007;94:894-902. [Crossref]

12. Tsai BM, Wang M, Pitcher JM, Kher A, Crisostomo P, Meldrum DR. Zaprinast attenuates hypoxic pulmonary artery injury and causes less aortic relaxation than milrinone. Shock 2005;24:41720. [Crossref]

13. Jones OM, Brading AF, McC Mortensen NJ. Phosphodiesterase inhibitors cause relaxation of the internal anal sphincter in vitro. Dis Colon Rectum 2002;45:530-6. [Crossref]

14. Williams SJ, Parsons ME. Nitric oxide, an enteric nonadrenergic-noncholinergic relaxant transmitter: evidence using phosphodiesterase $\mathrm{V}$ and nitric oxide synthase inhibition. Br J Pharmacol 1995;116:1789-96. [Crossref]

15. Huang LY, Liu YX, Wu CR. Application ofendoscopic retrograde cholangiopancreatography in biliarypancreatic diseases. Chinese Med J 2009;122:2967-72.
16. Shah V, Lyford G, Gores G, Farrugia G. Nitric oxide in gastrointestinal health and disease. Gastroenterology 2004;126:903-13. [Crossref]

17. Rochester JS, Jaffe DL. Minimizing complications in endoscopic retrograde cholangio pancreatography and sphincterotomy. Gastrointest Endosc Clin N Am 2007;17:105-27. [Crossref]

18. Potter LR. Guanylyl cyclase structure, function and regulation. Cell Signal 2011;23:1921-6. [Crossref]

19. Buechler WA, Nakane M, Murad F. Expression of soluble guanylate cyclase activity requires both enzyme subunits. Biochem Biophys Res Commun 1991;174:351-7. [Crossref]

20. Bagcivan I, Kaya T, Turan M, Karadas B, Sarac B, Duman M. Comparative relaxant effects of YC-1 and DEA/NO on the sheep sphincter of Oddi. Pancreatology 2006;6:215-9. [Crossref]

21. Murray JA, Du C, Ledlow A, Manternach PL, Conklin JL. Guanylate cyclase inhibitors: effect on tone, relaxation, and cGMP content of lower esophageal sphincter. Am J Physiol 1992;263:97-101.

22. Friebe A, Mergia E, Dangel O, Lange A, Koesling D. Fatal gastrointestinal obstruction and hypertension in mice lacking nitric oxide-sensitive guanylyl cyclase. Proc Natl Acad Sci U A 2007; 104:7699-704. [Crossref]

23. Schäfer A, Fraccarollo D, Werner L, Bauersachs J. Guanylyl cyclase activator ataciguat improves vascular function and reduces platelet activation in heart failure. Pharmacol Res 2010;62:4328. [Crossref]

24. Rotella DP. Phosphodiesterase 5 inhibitors: current status and potential applications. Nat Rev Drug Discov 2002;1:674-82. [Crossref]

25. Goldstein I, Lue TF, Padma-Nathan H, Rosen RC, Steers WD, Wicker PA. Oral sildenafil in the treatment of erectile dysfunction: Sildenafil Study Group. N Engl J Med 1998;338:1397-404. [Crossref]

26. De Witt BJ, Marrone JR, Kadowitz PJ. Comparison of responses to siguazodan, rolipram, and zaprinast in the feline pulmonary vascular bed. Eur J Pharmacol 2000;406:233-8. [Crossref]

27. Galiè N, Ghofrani HA, Torbicki A, Barst RJ, Rubin LJ, Badesch $\mathrm{D}$, et al. Sildenafil citrate therapy for pulmonary arterial hypertension. N Engl J Med 2005;353:2148-57. [Crossref]

28. Eherer AJ, Schwetz I, Hammer HF, Petnehazy T, Scheidl SJ, Weber K, et al. Effect of sildenafil on oesophageal motor function in healthy subjects and patients with oesophageal motor disorders. Gut 2002;50:758-64. [Crossref]

29. Cheon YK, Cho YD, Moon JH, Im HH, Jung Y, Lee JS, et al. Effects of vardenafil, a phosphodiesterase type-5 inhibitor, on sphincter of Oddi motility in patients with suspected biliary sphincter of Oddi dysfunction. Gastrointest Endosc 2009;69:1111-6. [Crossref]

30. Barnette MS, Barone FC, Fowler PJ, Grous M, Price WJ, Ormsbee HS. Human lower oesophageal sphincter relaxation is associated with raised cyclic nucleotide content. Gut 1991;32:4-9. [Crossref] 